\title{
Processing of oats and the impact of processing operations on nutrition and health benefits
}

\author{
Eric A. Decker ${ }^{1,2 *}$, Devin J. Rose ${ }^{3}$ and Derek Stewart ${ }^{4,5}$ \\ ${ }^{1}$ Department of Food Science, University of Massachusetts, Amberst, MA 01003, USA \\ ${ }^{2}$ Bioactive Natural Products Research Group, Department of Biochemistry, Faculty of Science, \\ King Abdulaziz University, P. O. Box 80203 Jeddah, 21589, Saudi Arabia \\ ${ }^{3}$ Department of Food Science and Technology, University of Nebraska-Lincoln, 143 Filley Hall, Lincoln, NE 68583, USA \\ ${ }^{4}$ Environmental and Biochemical Sciences, The James Hutton Institute, Dundee DD2 5DA, Scotland, UK \\ ${ }^{5}$ BioForsk Nord-Holt, PO Box 2284, Trømso, Norway
}

(Submitted 3 October 2013 - Final revision received 4 June 2014 - Accepted 17 June 2014)

\begin{abstract}
Oats are a uniquely nutritious food as they contain an excellent lipid profile and high amounts of soluble fibre. However, an oat kernel is largely non-digestible and thus must be utilised in milled form to reap its nutritional benefits. Milling is made up of numerous steps, the most important being dehulling to expose the digestible groat, heat processing to inactivate enzymes that cause rancidity, and cutting, rolling or grinding to convert the groat into a product that can be used directly in oatmeal or can be used as a food ingredient in products such as bread, ready-to-eat breakfast cereals and snack bars. Oats can also be processed into oat bran and fibre to obtain high-fibrecontaining fractions that can be used in a variety of food products.
\end{abstract}

Key words: Oats: Processing: Lipase: Processed food: Minimally processed food: $\beta$-Glucan: Fibre

Food-processing operations are essential to converting agricultural commodities into foods that can be eaten by, and are palatable and appealing to, consumers. Through various physical and chemical operations, food processing can increase shelf-life, improve bioaccessibility of nutrients, stabilise the colour and flavour, increase economic value and facilitate the preparation of raw food ingredients ${ }^{(1)}$. Cereal grains are evolutionarily designed to be chemically, physically and biologically inactive until the proper conditions allow the seed to germinate into a new plant. This makes cereal grains a great biological tissue for the long-term storage of important micro- and macronutrients for both livestock and human beings. However, unprocessed cereal grains are not readily digestible, so they must be processed to convert them into a palatable and nutritious food ${ }^{(2)}$. This is primarily because the outer portion of the seed (the hull) is designed to protect the seed from harsh environments. The hull is so effective that, if the seed is consumed unprocessed, it can pass through the entire digestive system with little or no digestion - a reproduction strategy of the plant to increase seed dispersal. Milling and other processing steps are therefore essential in converting the seed to food. The development of cereal processing has been extremely important in making cereal grains one of the most important foodstuffs on the planet.
Oats have several unique properties that make their milling different from other cereal grains ${ }^{(3)}$ - their hull is not connected to the endosperm, they have a higher fat content than most cereal grains and they contain high levels of soluble dietary fibres. Oats have a hull that consists mainly of cellulose, hemicelluloses and lignin. Within the hull is the groat, which comprises $68-72 \%$ of the kernel $^{(4)}$. The oat is most commonly processed as a whole grain because its groat is softer than other grains such as wheat, and thus cannot be easily converted into separate germ, endosperm and bran fractions. The outer layer of the groat is an important source of protein, neutral lipids, $\beta$-glucan, phenolics and niacin, and is sometimes separated from the groat to produce oat bran. The inner endosperm consists of proteins, starch and $\beta$-glucan while the germ contains mainly lipids and proteins. These oat components and its unique physiological structure require that oats are processed differently from other grains, and also provide them with some unique nutritional qualities that make them an important, albeit underutilised and valued, food product and sometimes an ingredient in other food products. This article reviews the steps required for oat milling, the opportunities for extracting/concentrating unique components from oats for use as food ingredients and the further use of oat products in consumer food products. Many of the steps described later can vary from mill 


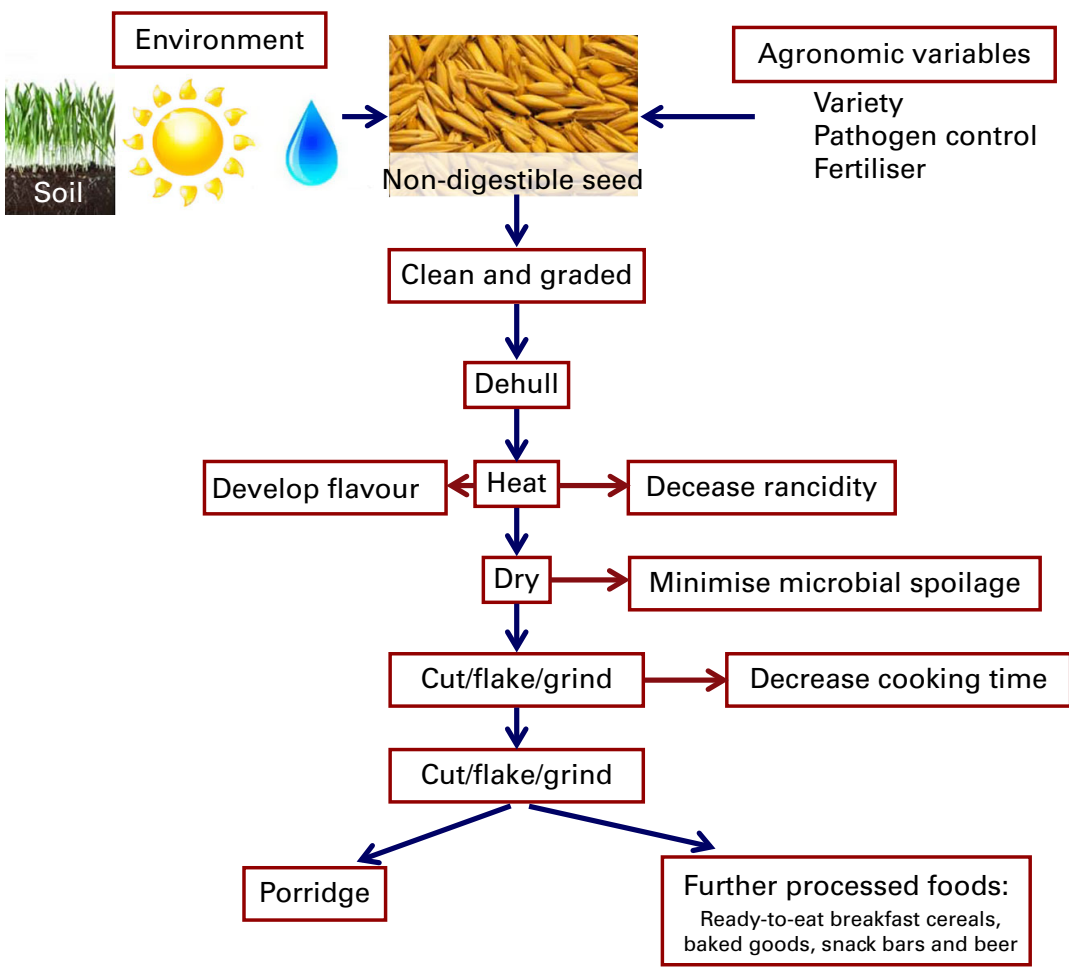

Fig. 1. A flow diagram showing the production of oats on the farm through typical oat-processing operations and production of human foods. The impact of processing operations on the farm variables is included in other sections in this special addition. How the quality of the oats is affected by some processing steps are included in the side boxes. A colour version of this figure can be found online at http://www.journals.cambridge.org/bjn

to mill, so the discussion is intended to give a broad overview of how oat grains are converted to human food (see also Fig. 1)

\section{Oat milling}

The quality of milled oats depends on plant genetics (varieties), agricultural practices, chemical composition, and storage and handling conditions. The genetics of the oat affects milling efficiency as kernel size and groat percentage affect yield. In addition, these factors will also be influenced by the growing environment and variations in climate, such as rainfall or frost. Chemical composition will affect both nutritional content and quality - for instance, high levels of NEFA are generally an indication of improper storage and handling that result in kernel damage, so that lipases can hydrolyse the TAG. The presence of NEFA decreases quality because they directly produce off-flavours and are more susceptible to developing oxidative rancidity ${ }^{(5)}$.

Proper storage and handling of oats is important to decrease nutrient loss and to minimise the formation of off-flavours resulting from lipid oxidation. When oats are stored in bulk, the moisture content of each individual kernel will adjust to reach equilibrium with its surrounding environment. Hence, storage conditions are an important food-preservation factor, as improper moisture control can result in the growth of micro-organisms that can cause spoilage and impose food safety risks (such as the formation of aflatoxins from mould growth) ${ }^{(6)}$. Excess temperatures can also decrease quality by increasing enzyme reactions, nutrient degradation and microbial growth, so it has been recommended that oats are stored at $<0.65$ water activity (approximately $13 \%$ moisture in the kernels) between 5 and $20^{\circ} \mathrm{C}^{(3)}$.

Overall, milling is designed to remove foreign materials, isolate and stabilise the groat and convert the groat into a form that is easy to cook. This involves cleaning, dehulling and kilning, and then cutting, flaking or producing flour. A more extensive review of milling and factors influencing milling efficiency are found in Girardet \& Webster ${ }^{(3)}$. The major steps of oat milling are described in the following.

\section{Cleaning}

As with numerous agricultural products, harvesting oats will lead to co-mingling of the oats with other components found in the field and transportation process ${ }^{(3)}$, and these foreign materials need to be removed to make oats suitable for human consumption. This is accomplished primarily by screening. When the oats enter the mill, they pass under a magnetic separator to remove foreign metal objects, a very common practice in many food-processing operations ${ }^{(7)}$. The oats then experience a series of rotating or oscillating screens that can both retain large objects (such as straw, sticks and stone) and let small objects such as underdeveloped oats, dirt, weed seeds and dust to pass through. The retained oat stream is then subjected to aspiration to remove more of the light materials. This is followed by a dry stoner that removes high-density but similar-sized particles such as rocks and other grains, such as maize.

In some cases, oats undergo clipping before cleaning ${ }^{(3)}$, cutting off the tip of the oats to make later dehulling 
more efficient. Clipping is done before cleaning so the clipped off portion can be removed before further milling. Clipping utilises a meshed screen into which the narrow end of the oat can penetrate. A rotating bar then displaces the oat from the mesh resulting in the tip being broken off, and the cut-off tips are removed by aspiration.

A rotary separator can also be used to sort the oats into different size classes, which can increase milling efficiency by eliminating small kernels that do not have a large percentage of groat $^{(3)}$. An indented rotary drum is used for this process. An indent separator is designed as its name implies, with indents on the inner face of a rotating cylinder that are the size of the seeds that are to be removed - an indent separator that is designed to remove the seeds of weeds has indents smaller than the oats, for example. The weed seeds fit tightly into the indents and are carried high up the side of the rotating cylinder, and the tight fit of the seed in the indent allows it to be carried far up the side of the cylinder until the pull of gravity drops the weed seed into a trough that is in the centre of the cylinder. The seeds in the trough are then removed by a screw conveyer and the larger oats, which are not lifted high enough up the side walls, continue to move out of the bottom of the cylinder. The size of the particle removed by the screw conveyer can be adjusted by adjusting the height of the catch trough. The lower the trough, the larger the particles that are separated, because even particles that do not tightly fit in the indents will rise up the sides of the cylinder due to friction. Some small oats such as light oats, double oats and pin oats can be removed by this process and are used as animal feed.

\section{Grading}

To operate the oat mill at maximum efficiency, the isolated oats must be divided into different sizes, which is done using the differences in the density and weight of the oat fractions $^{(3)}$. Most graders separate oats based on width, as this is the most accurate way to isolate oats with similar weights. Width separation uses a series of perforated cylinders. The first has an intermediate perforation that allows the small- and medium-width oats to pass through the cylinder, with the larger oats being carried out of the end of the cylinder (over-tail). The small and medium oats then enter a second perforated cylinder with smaller holes, which allow the smallest oats to pass through.

\section{Dehulling}

The hull is highly indigestible, so it must be removed to obtain maximum nutritional benefits. In modern mills, the first step of dehulling is a rotating disc that has numerous fins running from the centre of the disc to the exterior ${ }^{(3)}$. The oats fall into the centre of this rotating disc and are thrown into a series of impact rings on the wall of the dehuller, which causes the groat to be separated from the hull. This process continues until approximately $85 \%$ of the oats are dehulled as too much dehulling will cause the groats to break, which decreases the yield. The efficiency of dehulling is dependent on oat weight and moisture content, and the throughput of the dehulling machine, which is why the oats are graded into similar weights before dehulling. Rotation speed of the disc can be adjusted to increase the efficiency of dehulling without causing groat breakage - for example, larger oats require lower speed of rotation to separate the hull compared to the speed required for small oats. Moisture strongly impacts dehulling efficiency with high moisture decreasing dehulling and low moisture increasing groat-breakage rates: a moisture content of $12-13 \%$ is ideal. Overall, dehulling produces a mixture of hulls, groats, unhulled oats and broken groats that must be further separated.

Following dehulling, the oat stream is subjected to aspiration to remove the hulls and fines (small particles formed by breakage). The mostly dehulled oats are then passed through a cylinder with a rough interior to scour off any adhering hulls followed by a second aspiration. The oat stream is then passed through a table or paddy separator, which separates groats from the unhulled oats based on differences in density and smoothness of the particles. The groats have a smoother texture and higher density than unhulled oats, so they move more quickly through the separator. The oat stream enters a tilted table containing a series of bumpers, not unlike a pin-ball machine. The table then rocks back and forth on its longitudinal axis causing the oat stream to bounce off of the bumpers. The smoother and denser groats move towards the bottom while the unhulled oats rise to the top. The unhulled oats are then returned to the dehuller. For end products requiring high levels of dehulled oat removal (such as cut oats), several table separators are used in series. Finally, a perforated drum separator is used to remove contaminating grains such as wheat and barley that are larger than the groats ${ }^{(3)}$.

\section{Kiln drying}

Oats are somewhat unusual in that they contain 6-8\% fat compared to $2-3 \%$ fat in most other grains. Oats also contain high PUFA (35\% linoleic acid; see Stewart \& McDougall ${ }^{(8)}$ ) and high levels of lipid-digesting enzymes. The main forms of lipids in oats are phospholipids and TAG that are susceptible to hydrolysis by lipase into NEFA. Oats tend to have higher lipase activity than other grains (Table 1). The NEFA produced by lipase not only have an unappealing soapy taste but can also react with lipoxygenases, which catalyse the conversion of unsaturated fatty acids (most commonly linoleic acid) into fatty acid hydroperoxides. These hydroperoxides can decompose into a series of volatile fatty

Table 1. Activity and optimum $\mathrm{pH}$ and temperature of lipase in selected whole grains

\begin{tabular}{lccc}
\hline Grain & Lipase activity $\left(\right.$ units $\left.^{\star} / \mathrm{g}\right)$ & $\mathrm{pH}$ & Temperature $\left({ }^{\circ} \mathrm{C}\right)$ \\
\hline Rice & $11-13$ & $7.5-8 \cdot 0$ & $35-40$ \\
Oats & 20 & $7 \cdot 4-7.5$ & $35-39$ \\
Wheat & $2-4.5$ & $7 \cdot 2-8.2$ & 40 \\
\hline
\end{tabular}

* One unit was defined as $\mu \mathrm{mol}$ fatty acids released per hour under the conditions of the assay. 
acid decomposition products, such as hexanal, which produce rancid $\operatorname{aromas}^{(5)}$.

In the intact grain kernel, lipase and lipoxygenase are physically compartmentalised, so they do not react with TAG and phospholipids. However, during milling, most compartmentalisation is destroyed, allowing the enzymes and lipids to interact. Therefore, to control off-flavour development before this decompartmentalisation, lipase and lipoxygenase must by inactivated by heat denaturation. This is accomplished by first applying live steam (steaming) and then applying heat for an extended period, known as kilning. An additional advantage of kilning is that it increases the Maillard reaction, which is a reaction between proteins and carbohydrates that produces desirable flavours, browning and the formation of antioxidant compounds that further increase the stability of lipids ${ }^{(5)}$.

Kilning is most commonly conducted by placing the groats in long vertical cylinders and then injecting steam and air into the columns ${ }^{(3)}$. The live steam is injected into the top of the column to increase the temperature of the groat rapidly. The steam increases the moisture content of the groats, which is advantageous because the efficiency of enzyme inactivation increases with increasing moisture content. However, increased moisture content of the groats can reduce the quality and storage stability of the final products, so further down the column the groats are subjected to radiant heating (dry heat) to evaporate excess moisture. An added advantage of radiant heating is that this accelerates the Maillard reaction, producing desirable nutty flavours and caramel colours. Towards the end of this process, air is injected into the groats to decrease temperature and remove moisture to a final water content of $10 \%$. The effectiveness of enzyme inactivation is monitored by measuring peroxidase activity. Peroxidase is more heat stable than lipase and lipoxygenase, so its complete inactivation ensures that lipase and lipoxygenase are also inactivated.

Kilning is also advantageous to oat quality in that it can inactivate bacteria, yeasts and moulds that can decrease shelf-life and pose food safety risks ${ }^{(7)}$. However, as with all thermal-processing treatments, kilning will also destroy some heat-liable vitamins such as B vitamins - but the benefits of the ability of kilning to extend shelf-life far outweigh these undesirable effects.

\section{Converting groats to food ingredients and products}

After milling, the final products include whole groats (Fig. 2(a)) of varying sizes, broken groats and powdered fines. These different products can be used to make oat flakes, steel-cut oats, oat flour and oat bran, and in some cases can be used to produce oat ingredients such as fibre.

\section{Cutting}

Steel-cut oats are produced by simply cutting the whole groats into smaller pieces (Fig. 2(b)). This is accomplished by a rotary granulator ${ }^{(3)}$, which consists of a perforated drum with steel knives on the outside. The drum is rotated and
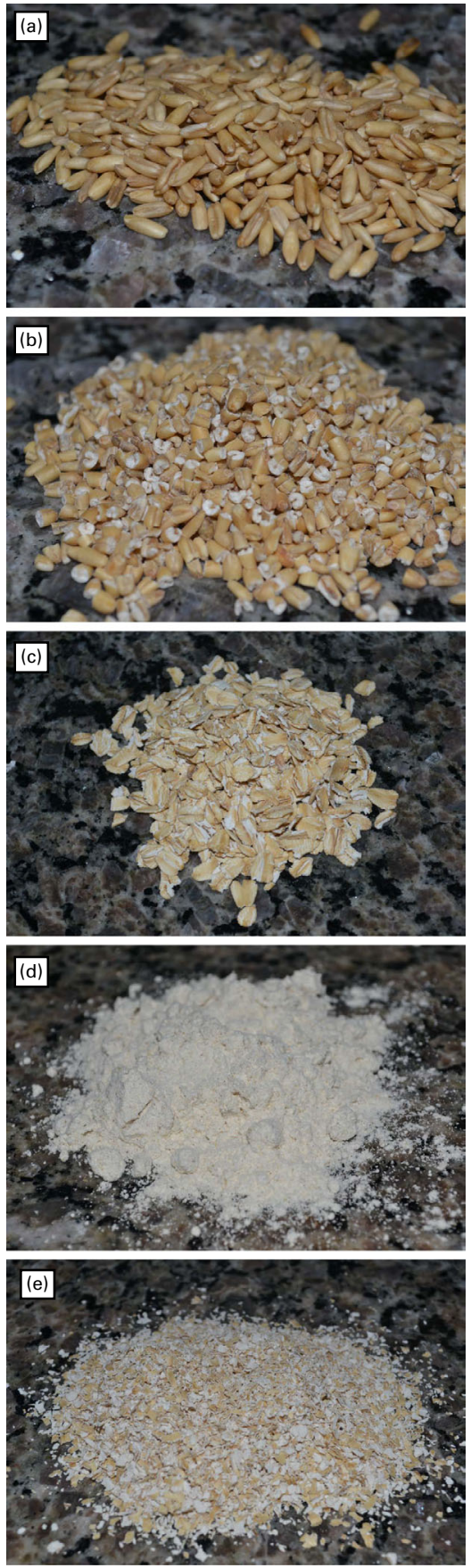

Fig. 2. Photographs of oat groats (a), steel cut oats (b), rolled oats (c), oat flour (d) and oat bran (e) that show differences in physical appearance due to processing. A colour version of this figure can be found online at http://www.journals.cambridge.org/bjn

the knives cut the partition of the groat that extends through the perforation. Typically, each groat is cut two to four times. Many factors affect the size of the cut groat, including rotation speed, position of the knives, size of the perforations and the initial size of the groat. Small amounts of fines $(<2 \%)$ are produced by this process and are removed by a shifter. Different sizes of cut oats are separated by an indent cylinder similar to the device described in the cleaning section. 


\section{Flaking}

Oat flakes (Fig. 2(c)) are produced simply by flattening either whole or steel-cut groats with two rotating rollers ${ }^{(3)}$. However, the groats exiting kiln drying are very susceptible to crushing into powder because of their low moisture content. To avoid this, before rolling, the groats are exposed to steam during agitation before rolling, with the goal of adding 3-5\% moisture. This process can take $20-30 \mathrm{~min}$ and will increase the temperature of the groats. In an optimal process, moisture equilibration should be achieved with the smallest possible temperature increase over the shortest time to minimise nutrient degradation.

Flake thickness can be controlled by adjusting the distance between the rollers: the thinner the flake the faster they $\operatorname{cook}^{(9)}$. In general, quick-cooking flakes are rolled thinner $(0.36-0.46 \mathrm{~mm})$ than whole-oat flakes $(0.51-0.76 \mathrm{~mm})$. Even thicker flakes are produced for products such as muesli. The thickness of the flakes can vary from $0.7-1.2$ to $<0.4 \mathrm{~mm}$ for quick-cooking oats. After rolling, the flakes are passed through an air stream to decrease both their temperature and moisture content, returning the flakes to $10-12 \%$ water. Finally, the flakes pass over a shaking shifter to break apart clumps of flakes and remove fines and small flakes ${ }^{(3)}$.

The combination of steam followed by drying can cause the starch in the oat flakes to become partially pre-gelatinised. Pre-gelatinised starch will more rapidly absorb watered than unprocessed starch, thus decreasing the cooking time ${ }^{(10)}$.

\section{Flour}

Groats or oat flakes can be ground with a pin or hammer mill into flour. During grinding, the oat flour (Fig. 2(d)) tends to clump due to its high fat content, so air is used to move the flour through the mill and decrease heat build-up. After exiting the mill, the flour goes through a vibrating shifter this removes the remaining large particles, which are recycled into a second milling. Oat flour is primarily used for baby food and ready-to-eat cereals ${ }^{(3)}$

\section{Oat bran}

Oat flour can be separated into coarse and fine fractions. The coarse fraction is referred to as bran (Fig. 2(e)) that comes from the outer aleurone and subaleurone layers of the groat and is higher in fibre, protein, vitamins and minerals, and is slightly higher in fat. The fine fraction has a high starch content. The coarser bran fraction is separated by shifting the oat flour. According to the American Association of Cereal Chemists ${ }^{(11)}$ and the US Food and Drug Administration, oat bran must have a total dietary fibre content of at least $16 \%$, with one-third of the fibre being soluble and a $\beta$-glucan content of at least $5 \cdot 5 \%$.

\section{Oat hulls}

Oat hulls constitute $28-32 \%$ of the oat and thus represent a challenge for by-product utilisation. The hulls contain
$30-35 \%$ fibre, $30-35 \%$ pentosans, $10-15 \%$ lignans, protein and ash - the latter is high in silicic acid ${ }^{(3)}$. If the hulls are finely ground, they can have application as high-fibre animal feed and human food ingredient applications. Recently, oat hulls have been used as biomass for power plants - for example, oat hulls from a General Mills food-processing plant are used in a nearby biomass power plant to produce enough electricity to power over 17000 homes $^{(12)}$. There is a similar partnership between the University of Iowa and Quaker Oats with oat hulls replacing coal and supplying over $10 \%$ of the university's energy needs. Oat hulls can also be used as a source of cellulosic fibre using alkaline treatments $^{(13)}$.

\section{Concentrated $\beta$-glucan}

Several techniques can be used to process oat grain into fractions that are higher in $\beta$-glucan. This is accomplished by dry milling techniques to remove the starch from oat bran $^{(13)}$, which can be done by drying the oat bran and then conducting an additional grinding or rolling step to help release the starch from the $\beta$-glucan. The fibre and starch fractions are then separated by sieving and aspiration. $\beta$-Glucan concentrations can be increased to $12-22 \%$ by using these processes.

$\beta$-Glucan concentrations can also be increased by solubilising the $\beta$-glucan with water, heat and shearing to decrease viscosity $^{(13)}$. This slurry can then be passed through a sieve or centrifuged to separate non-solubilised components such as starch. Alternatively, $\beta$-glucan can be concentrated by utilising enzymes that degrade starch, protein and lipid. This can be done by simply adding water to the oats and allowing the endogenous enzymes to digest the non-fibre components ${ }^{(13)}$. Exogenous $\alpha$-amylase and trypsin ${ }^{(14)}$ can also be added to aid in the hydrolysis of starch. These techniques can increase $\beta$-glucan concentrations used in high-fibre foods, and, because they can be used to increase viscosity, they can also be used to replace fats in certain foods. However, these are multiple-step processes, meaning that enrichment leads to a net increase in price per $\mathrm{kg}$ compared to the original oat.

\section{Oat-based foods}

The most common way to eat oats is oatmeal, and several different types of oatmeal can be purchased in most grocery stores, including regular, quick-cooking and Irish and Scottish oatmeal $^{(9)}$. To make oats more digestible and easier to eat (namely, softer), the starch in the groat must become gelatinised $^{(10)}$. Starch consists of granules made up of of two different glucose-containing polysaccharides: amlyose and amylopectin. Converting oats into a more desirable food requires heating the starch in the presence of water so the water can move into the granule, allowing it to swell and become soft. Quick-cooking oatmeal contains oat flakes that are thinner than regular (e.g. old fashioned) oatmeal, so their starch can absorb water more quickly and thus decrease the cooking time. Irish oatmeal contains steel-cut oats and thus has the longest cooking time ${ }^{(9)}$. Scottish oatmeal is a 
coarsely ground meal that also takes a long time to cook and has a consistency of porridge. The creamy texture of oatmeal comes from the water-binding properties of its soluble fibres.

Ready-to-eat breakfast cereals are most commonly made from a batter containing oat flour, and are extruded (expanded) or rolled and baked. The starch granules in these products can easily absorb moisture and will therefore soften without cooking, such as when they are mixed with milk. Oats are also used to make products such as granola, snack bars, cookies and pancakes, and are used as an extender in meat products such as black and white puddings and haggis, and as a carbohydrate source for fermented foods such as beer. The lipid in many grains including oat can exist as lipid bodies ${ }^{(15)}$, which are like emulsion droplets with the lipids surrounded by phospholipids and proteins. The lipid bodies, along with proteins, can be extracted from oats using water and salt to produce oat milk ${ }^{(16,17)}$.

An added advantage of oats as a food ingredient is that they do not contain gluten: they have avenins as their storage proteins. Thus, they can be used in gluten-free foods targeted at people with coeliac disease because avenins are less likely to cause allergies even among coeliac sufferers ${ }^{(18,19)}$. The oats used in these products must be very pure and not contain wheat contamination. Unfortunately, the lack of gluten prevents oat flour from being used as the sole flour in raised breads, because gluten produces the needed elasticity and structure to bread dough that allow it to properly rise, whereas avenins do not have this ability - hence, most oat breads still contain wheat flour.

\section{Impact of processing on products' nutritive and healthy beneficial value}

As mentioned earlier, the unique composition of oats, combined with their subsequent processing, add to the unique organoleptic and nutrient experience accompanying the consumption of oat products. However, the processing of oats into foods accepted by consumers can result in changes in their nutritional composition. Recent studies by Zhang et $a l{ }^{(20)}$ into the impact of processing and storage on fortified oat beverages (oat milks ${ }^{(16,17)}$ ) highlighted that ultra-high temperature pasteurisation $\left(5-20 \mathrm{~s}\right.$ at $\left.140^{\circ} \mathrm{C}\right)$ required to ensure microbiological stability had minimal impact on vitamin content. However, prolonged storage up to 12 months resulted in the degradation of linolenic acid and vitamins $\mathrm{A}$, $\mathrm{D}_{3}$ and $\mathrm{B}_{12}$. In addition, oat tocopherols and tocotrienols (in combination known as tocols, of which a-tocotrienol comprises $57-99 \%$ of total oat tocols) suffer degradation due to elevated temperature-processing operations such as baking and extrusion ${ }^{(21)}$.

Interestingly, heated extrusion has been shown to improve the functional properties of oat bran, leading to the extruded bran having more aggregates, higher gelatinisation temperature, higher solubility, swelling capacity, increased apparent viscosity and a decrease in the flow behaviour index ${ }^{(22)}$. The latter two changes have been proposed to be beneficial, as they could contribute to a slower gut transit and the perceived 'fuller for longer' of satiety effect ${ }^{(23-25)}$. Extrusion has also been found to alter $\beta$-glucan's ability to decrease serum cholesterol. In breakfast cereals containing $3 \mathrm{~g}$ of $\beta$-glucan/ serving, high molecular weight $\beta$-glucan $(>530000 \mathrm{~g} / \mathrm{mol})$ was able to decrease LDL-cholesterol. However, when the molecular weight of $\beta$-glucan was $<210000 \mathrm{~g} / \mathrm{mol}$, the ability of the breakfast cereal to reduce LDL-cholesterol was decreased by $50 \%{ }^{(26)}$.

\section{Conclusions}

Oats represent a uniquely nutritious food with an excellent lipid profile and high amounts of soluble fibre. However, an oat kernel is largely non-digestible and thus must be used in milled form if its nutritional benefits are to be realised. There are numerous steps in the milling process, the most important of which are dehulling to expose the digestible groat, heat processing to inactivate enzymes that cause rancidity, and cutting, rolling or grinding to convert the groat into a product that is a more convenient food, more able to be rapidly cooked and/or incorporated into other food products.

\section{Acknowledgements}

E. A. D., D. J. R., and D. S. each received an honorarium from Quaker Oats Company (a subsidiary of PepsiCo, Inc.) for attending a workshop in May 2012 to discuss the content of the supplement. E. A. D. (The University of Massachusetts), D. J. R. (The University of Nebraska) and D. S. (The James Hutton Institute) each received an unrestricted grant from the Quaker Oats Company.

D. S. is part of the QUOATS Consortium (http://www. quoats.org) that is jointly sponsored by BBSRC, DEFRA, SG-RESAS, WAG, AHDB and industry partners. D. S. acknowledges grant-in-aid and contract research funding from SG-RESAS for strategic research and MACSUR (http://www. macsur.eu) activities, respectively.

The authors' contributions are as follows: E. A. D. reviewed articles for inclusion, and drafted the paper. D. S. and D. J. R. contributed to writing and editing the paper.

This paper was published as part of a supplement to British Journal of Nutrition, publication of which was supported by an unrestricted educational grant from Quaker Oats Co. (a subsidiary of PepsiCo Inc.). The papers included in this supplement were invited by the Guest Editor and have undergone the standard journal formal review process. They may be cited.

The Guest Editor to this supplement is Roger Clemens. The Guest Editor declares no conflict of interest.

\section{References}

1. Fellows P (2004) Processed Foods for Improved Liveliboods. Rome: Agricultural Support Systems Division, Food and Agriculture Organization of the United Nations. (FAO Diversification Booklet 5)

2. Serna-Saldivar SO (2010) Cereal Grains: Properties, Processing, and Nutritional Attributes. Boca Raton, FL: CRC Press.

3. Girardet N \& Webster FH (2011) Oat milling: specifications, storage, and processing. In Oats: Chemistry and Technology, 
2nd ed., pp. 301-316 [FH Webster and PJ Wood, editors]. St Paul, MN: American Association of Cereal Chemists.

4. Webster FH (1996) Cereal grain quality. In Cereal Grain Quality, pp. 179-203 [RJ Henry and PS Kettleman, editors]. London: Chapman and Hall.

5. McClements DJ \& Decker EA (2008) Lipids. In Fennema's Food Chemistry, pp. 155-216 [S Damodarin, K Parkin and OR Fennema, editors]. Boca Raton, FL: CRC Press.

6. Labbé RG \& García S (2011) Guide to Foodborne Pathogens. Hoboken, NJ: John Wiley \& Sons.

7. Fellows P (2009) Food Processing Technology: Principles and Practice. Cambridge, UK: Woodhead Publishing.

8. Stewart D \& McDougall G (2014) Oat agriculture, cultivation and breeding. Br J Nutr 112, S50-S57.

9. McGee H (2004) On Food and Cooking: The Science and Lore of the Kitchen. New York, NY: Scribner.

10. BeMiller JN \& Huber KC (2008) Carbohydrates. In Fennema's Food Chemistry, pp. 83-154 [S Damodarin, K Parkin and OR Fennema, editors]. Boca Raton, FL: CRC Press.

11. American Association of Cereal Chemists (1989) Oat Bran Definition. http://www.aaccnet.org/initiatives/definitions/ Documents/OatBran/OatBran.pdf (accessed August 2013).

12. General Mills (2012) The Hidden Power of Oat Hulls. http:// www.generalmills.com/Company/Innovation/Our_stories/ OatHulls.aspx (accessed August 2013).

13. Stevenson DG \& Inglett GE (2011) Oat dietary fiber: commercial processes and functional attributes. In Oats: Chemistry and Technology, 2nd ed., pp. 321-328 [FH Webster and PJ Wood, editors]. St Paul MN: American Association of Cereal Chemists.

14. Mälkki Y \& Myllymäki O (1998) Method for enriching soluble dietary fibre. US patent no. 5,846,590.

15. Heneen WK, Banas A, Leonova S, et al. (2009) The distribution of oil in the oat grain. Plant Signal Behav 4, 55-56.
16. Onning G, Akesson B, Oste R, et al. (1998) Effects of consumption of oat milk, soya milk, or cow's milk on plasma lipids and antioxidative capacity in healthy subjects. Ann Nutr Metab 42, 211-220.

17. Onning G, Wallmark A, Persson M, et al. (1999) Consumption of oat milk for 5 weeks lowers serum cholesterol and LDL cholesterol in free-living men with moderate hypercholesterolemia. Ann Nutr Metab 43, 301-309.

18. Zimmer KP (2011) Nutrition and celiac disease. Curr Probl Pediatr Adolesc Health Care 41, 244-247.

19. Rashid M, Butzner D, Burrows V, et al. (2007) Consumption of pure oats by individuals with celiac disease: a position statement by the Canadian Celiac Association. Can J Gastroenterol 21, 649-651.

20. Zhang H, Onning G, Triantafyllou AO, et al. (2007) Nutritional properties of oat-based beverages as affected by processing and storage. J Sci Food Agric 87, 2294-2301.

21. Shewry PR, Piironen V, Lampi AM, et al. (2008) Phytochemicals in oat varieties in HEALTHGRAIN diversity screen. J Agric Food Chem 56, 9777-9784.

22. Zhang $M$, Bai $X$ \& Zhang $Z$ (2011) Extrusion process improves the functionality of soluble dietary fiber in oat bran. J Cereal Sci 54, 98-103.

23. Thies F, Masson LF, Boffetta P, et al. (2014) Oats and bowel disease: a systematic literature review. Br J Nutr 112, S31-S43.

24. Rose DJ (2014) Impact of whole grains on the gut microbiota: the next frontier for oats? Br J Nutr 112, S44-S49.

25. Clemens R \& van Klinken BJ-W (2014) The future of oats in the food and health continuum. Br J Nutr 112, S75-S79.

26. Wolever TMS, Tosh SM, Gibbs AL, et al. (2010) Physicochemical properties of oat ( $\beta$-glucan influence its ability to reduce serum LDL cholesterol in humans: a randomized clinical trial. Am J Clin Nutr 92, 723-732. 